\title{
Innovation, Science and Technology in the USA: a sociocultural perspective
}

Reed Elliot Nelson

FACCAMP - Southern Illinois University renelson@siu.edu 


\section{Abstract}

This paper traces the development of the Britsh/North American cultural matrix and its putative relation to scientific and technological innovation. I argue that peripheral position in the world system, early revolutions, and sectarian self selection mitigated state impediments to innovation that were common in much of Europe and the Americas. In the vacuum created by weak central control, entrepreneurial bricolage and protestant communitarianism facilitated the rapid creation and commercial diffusion of innovations. An interesting irony in this trajectory is the apparent frequency of the ancient bazar model of transaction in US high technology environments, albeit supported by high levels of societal trust uncommon in the original settings where this model of exchange developed.

Key words: Britsh/North American cultural matrix; Impediments to innovation; US high technology.

\section{Inovação, ciência e tecnologia nos EUA: uma perspectiva sociocultural}

\section{Resumo}

Este artigo traça o desenvolvimento da matriz cultural Britsh/Norte-americana e sua suposta relação com a inovação científica e tecnológica. Argumenta-se que a posição periférica no sistema mundial, as revoluções iniciais e a auto-seleção sectária atenuaram os impedimentos do estado para a inovação, que eram comuns em grande parte da Europa e das Américas. No vácuo criado pelo controle central fraco, a bricolagem empresarial e o comunitarismo protestante facilitaram a criação rápida e a difusão comercial das inovações. Uma ironia interessante nesta trajetória é a aparente frequência do modelo antigo de transação em ambientes de alta tecnologia dos EUA, embora suportado por altos níveis de confiança social incomum nas configurações originais onde este modelo de troca se desenvolveu.

Palavras-chave: Matriz Cultural Britânica /Norte Américana; Impedimentos para a inovação; US alta tecnologia.

Innovación, ciencia y tecnología en EE. UU .: una perspectiva sociocultural

\section{Resumen}

Este documento rastrea el desarrollo de la matriz cultural Bretaña / América del Norte y su supuesta relación con la innovación científica y tecnológica. Yo sostengo que la posición periférica en el sistema mundial, las primeras revoluciones y la auto 
selección sectaria mitigaron los impedimentos estatales a la innovación que eran comunes en gran parte de Europa y las Américas. En el vacío creado por el débil control central, el bricolage emprendedor y el comunitarismo protestante facilitaron la rápida creación y difusión comercial de innovaciones. Una ironía interesante en esta trayectoria es la aparente frecuencia del antiguo modelo de transacción Bazar en los entornos de la alta tecnología de EE. UU., aunque respaldado por altos niveles de confianza social poco comunes en los entornos originales donde se desarrolló este modelo de intercambio.

Palabras clave: Matriz cultural Británica / América del Norte; Impedimentos a la innovación; Estados Unidos alta tecnología.

\section{Introduction}

This essay is constructed around two assumptions. First is that any analytical view of a culture must start from a position of marginality. Only those who have left a system have the ability to interpret it. This can be illustrated by the old adage that "Fish know nothing about water". Our understanding of a given environment begins only when we are exposed to stimuli different from those to which we are accustomed. In my particular case, this is certainly true. What understanding I have of US culture, society and economy is intimately linked to my residential and travel experience outside of my country of birth, particularly Brazil and secondarily Asia, particularly Singapore and Hong Kong, and in Europe, Germany. As a result this essay will attempt to advance insights about science, technology, and innovation in the USA by posing contrasts to other national experiences, particularly Brazil.

The second assumption is that science, technology and innovation are ultimately the results of sociocultural processes, such that the emergence of any technological artifact, scientific construct, or new practice cannot be fully understood disembodied from its human environment (Barley, 1990; Berger \& Luckman, 1967; Lave, 1988; Ortony, 1993; Shenav, 1999). The apparent ease with which certain technologies migrate globally sometimes makes this difficult to see. And indeed there can be little doubt that science, technology, and innovations have important roles as independent variables influencing social systems (Barley, 1990; Nelson \& Vasconcelos, 2008). Moreover, it is equally axiomatic that there is a recursive relationship between the two forces: Technology molds culture and culture 
influences the generation of science, technology and innovation. I will make sporadic reference here to this recursive relationship, but my focus will be on society as an independent variable.

By making this second assumption I am self identifying my debt to Weberian sociology as opposed to the critical and Marxist traditions, which see technology as the independent variable which drives change in society. My assumption of this posture does not imply a value judgement about either of the paradigms, although I personally favor the Weberian posture. My intention is merely to alert readers to my conceptual inclinations and biases.

\section{The English Institutional Matrix versus the Iberian Institutional Matrix}

The Global Innovation Index (2017) is probably the most sophisticated approach to assessing national innovative capability in existence at present. The index takes account of a variety of factors from market sophistication, educational infrastructure, legal systems, scientific research capability, regulatory structure, and intellectual property rights and practices to arrive at an overall index of a nation's innovative capital. The rankings yield some striking findings if one partitions results by cultural subgroups. Of the top 20 countries in the rankings, eight are British possessions or former colonies. None of the top 20 are of Latin or Iberian heritage. Spain occupies $27^{\text {th }}$ place, Portugual $30^{\text {th }}$ place. Noteworthy also is the distribution of former colonies. Former British colonies USA, Singapore, Hong Kong, New Zeland, Australia and Canada rank within a standard deviation of England. They differ by a matter of a few points. The former lberian colonies do not fare as well as the former metropolis. Chile has the highest ranking of any former Spanish colony at 42, fifteen places behind Spain. Next come Costa Rica at 51, Mexico at 57, Panama at 62 and Columbia at 67 . The former Portuguese colonies are yet less fortunate. Brazil is closest to Portugal at 70-fully 40 places behind. Mozambique follows at 95, Cabo Verde at 103, and Angola at 120-90 places behind Portugal. We see then that not only does England possess one of the top rankings in terms of innovative capability, it has brought many of its colonies along, such that more than a third of the top 20 positions belong to Anglophone countries which are or were part of the English empire. By contrast, while both Spain and Portugal are now high income countries within the top quarter of the innovation rankings, none of their former possessions 
have done so well. Only Chile squeaks into the top third, followed at a distance by Mexico at 57. The former Portuguese colonies fare worse still. While Portugal is in $30^{\text {th }}$ place, its closest former colony, Brazil, is around the fiftieth percentile at 70 of 141 countries. Mozambique is $95^{\text {th }}$, Cabo Verde, $103^{\text {rd }}$, and Angola 120 (It should be noted however, that none of Britain's former African colonies rank in the top 30 percent, although they generally fare better than other African countries which were once European colonies.)

If we turn to patents per capita, which are a more focused indicator of the application of science to the generation of innovations as opposed to conditions that favor the generation and dissemination of innovations, the US holds third place accompanied in the top 20 by several other British possessions or former colonies. This result is quite close to its position on the global competitive index. The former Iberian possessions however, do better in patents than they do on the Global Competitiveness Index. Spain is $32^{\text {nd }}$ and Portugual $63^{\text {rd }}$, while Brazil is $50^{\text {th }}$ and Argentina for instance is $51^{\text {st }}$. Without engaging in much detailed discussion and analysis, it would appear that the scientific capacity to generate new artifacts is somewhat better for the former Iberian possessions than the ability to generate new waves of prosperity from those artifacts. This is consistent with a host of qualitative observations from a variety of sources (Guillén, 2001; Harrison, 1985). Generating new artifacts is one thing. Distributing them across a population in a way that stimulates prosperity and further inventiveness is more challenging. The Soviet Union and even North Korea were able to apply science to generate technical innovations by dedicating a large proportion of GDP to military science and technology, but they failed utterly at using this technological ability for economic purposes. The English cultural heritage appears to execute both functions well.

\section{Peripherial Position and Early Revolution}

What is it about the English environment that accounts for this and are the North American experience and capacity any different? Despite a welter of intervening variables, historical accidents and path dependent facts, I would like to argue here that two factors have considerable relevance to both the English and American experience with innovations, technology and science: peripheral position, 
and early revolutions.

Although the British Isles culturally and geographically belong to Europe they have always preserved a certain degree of distance and marginality from the continent. This isolation is longstanding. A substantial piece of England belonged to the Roman empire, but Britain lay at the outer sphere of the empire and a substantial part of the islands were also never taken by the Romans. Perhaps as a result, Britain was not assimilated into the empire in the same way that other parts of Europe were. The southern regions of the Iberian peninsula by contrast were fully integrated into the empire. The facility of contact provided by the Mediterranean sea and warmer climate meant both greater population density and easier contact with the metropolis for Hispania and even Gaul (now France) than England. Not only was the proportion of Roman citizens living in England smaller than in Hispania, the overall population density was lower. This intimacy with Rome is felt to this day in the language, culture, and institutions of the peninsula. Thus for at least half a millennium Rome influenced but did not fully dominate Britain, creating subcultural and political diversity and perhaps a sense of independence and self reliance that did not exist on the continent.

Over a thousand years later a similar dynamic was repeated in Spanish South America where Argentina's excellent port on the Atlantic coast facilitated its integration into the Spanish empire while Chile's low population and isolation on the Pacific coast left it on the periphery (Harrison, 1985; Wallerstein, 1980). If peripherality facilitates innovation, it is then perhaps not coincidental that that Chile has the highest ranking of the former Spanish colonies on the innovativeness index, far in front of Argentina. The Brazilian case is even less peripheral. Not only was it relatively easy to reach the capitals of Salvador, Recife and even Rio by ship from Portugal, the literal dislocation of the capital of the empire to Rio de Janeiro during the Napoleonic wars meant that Brazil was in many ways more thoroughly connected to the metropolis than were the Spanish colonies. This centrality makes for institutional and cultural continuity that can hamper change.

The marginality of Britain vis a vis the general sweep of European and Mediterranean history probably facilitated my second factor-early revolutions (Jenkins, 2012). In the $9^{\text {th }}$ century, the Norman invasion of England substituted most of the local elite with foreign conquerors. However, like the Roman invasion that preceded it, the conquerors had difficulty maintaining control over their new domain. 
Perhaps again because of the isolation of England by the channel and because of a low density population dispersed over a large area, central authority was weaker than elsewhere on the continent. By 1215 the very descendants of the Norman invaders rebelled against the king and forced him to sign a document - the magna cartaformally restricting his prerogatives. This had never been done before and nothing similar would happen in other European countries for at least another 400 years. The deliberative body that emerged from this first of many confrontations with the central power became a model for modern democratic legislatures. By the early 1400 s serfdom was waning in England because of labor shortages and ample unproductive land (By contrast, serfdom wasn't abolished in Russia till a few decades before the Bolshevik revolution in 1919, some 500 years later.) In 1488 the English king accepted a parliamentary mandate that taxes could not be imposed without a vote by elected representatives - another first, and one which was never violated in the metropolis. Its violation in the American colonies would eventually provide one impetus for the American revolution. All of these historical developments and more turned English attention away from a preoccupation with lobbying the central government for benefits or protections toward local self regulation and independent economic development.

While the English were slowly eroding the caprice of the king and later of the nobles and replacing it with robust local institutions, something very different was happening on the Iberian peninsula. Into the vacuum created by the decline of the Roman empire, the Moors were expanding aggressively via the Mediterranean sea. By 700 AD Islamic caliphates controlled most of the peninsula. The removal of the moors or "Reconquista", would occupy the attentions of the Iberian nobility for the approximately the next 700 years, slowly at first but then with increasing intensity (Gibson, 1967). While England slowly curbed the power of the crown and decreased the power of the nobility, the Iberians slowly consolidated the power of the crown using many elements of the Roman model which had dominated the region for many centuries. At the same time the power of the nobility remained strong because the central government needed the help of an aggressive warrior class to dislodge Islam. The result was a state which evolved around conquest and control and privilege for those willing and able to occupy hostile territory physically and negotiate personalistic benefits from the crown based on their success. The last of the Moorish kingdoms 
were defeated in 1492, just in time for the discovery of the Americas. It then became a simple-indeed, an almost inevitable-- matter for the Spanish and Portuguese to deploy the same mechanisms of conquest, control, and distribution of economic prerogatives to subjugate large portions of the new world. Neither the organizational tools adapted to a 700 year long military contest, nor the original Roman mechanisms for subjugating and governing territory were particularly well suited for the development of science, technology, nor the development of markets and institutions suited to deploy innovations arising from science and technology. Nor was orthodox Catholicism locked in a life and death struggle with Islam inclined to look at theological matters in a flexible way. The el dorado created by the unprecedented flow of gold from the colonies further dampened motivation to do anything other than extract wealth from the colonies ad lobby for its favorable distribution and disposition by the crown. As a result, manufacturing and technology were neglected by lberia during the colonial period while England was happy to supply Iberian markets with goods in exchange for hard currency, not unlike the Chinese are doing with the west today. The resulting inflow of gold to Britain provided capital for the incipient industrial revolution, which in England took place at least a century before significant industrial expansion on the continent. It might be said that Iberia never recovered from the side effects of easy prosperity based on conquest and exploitation of native populations' exportable surplus (Harrison, 1985; Wallerstein, 1980). By the time that England was in a position to do the same to India and Africa, she was already the world's premier industrial power, ready to offer competitive manufactured goods to markets everywhere.

\section{The North American Experience: Evangelicals and Bricoleurs}

In many ways, the Experience of the American Colonies represents a natural extension or unfolding of the decentralizing and liberalizing forces that were set loose during the long set of confrontations and negotiations that resulted in the British democracy. The English colonies, like England herself, lie at the periphery of the existing world economic and political system (Middlekauff, 2002; Wallerstein, 1980) and were sparsely populated. And unlike the Spanish colonies which had been established through the subjugation of dense native populations (the Portuguese case being rather different of course), the North American British colonies consisted 
initially of immigrants from Europe. What's more, especially in the beginning, most of these immigrants were fleeing what they perceived to be political or religious oppression or persecution in their native lands. This selection mechanism-people who moved to the colonies migrated because of deep grievances against perceived government abuses--resulted in a major amplification of the already existing English resistance to central authority. Further, their location at the periphery of the English empire inclined them toward independence, autonomy, and practicality. The fact that different groups of immigrants migrating to different colonies tended to be of different religious and cultural orientations forced them to be grudgingly tolerant of other groups. The nobility which continue to play a role in England until the present, was almost totally absent in the American colonies, and political appointees which came from the metropolis were distrusted and associated with the oppressors that had led to their flight from an oppressive government in the first place. Add to this the wholesale adoption of English common law practices granting ample judicial autonomy to localities and establishing representative governing bodies, and the stage was set for a political and economic system in which the state is minimally intrusive but also minimally helpful as an arbiter of public economic interests.

The isolation of the colonies in terms of both government and resource flows impacted innovation also. Unlike the Iberoamerican colonies which were prohibited from local manufacture and trade with other partners except Spain and Portugual, the Americans were generally able to trade with all comers and left to their own designs to manufacture items which they could not import. The nontropical climate also impeded cultivation of the kinds crops that tropical American colonies like the Bahamas sent to Europe (with the exception of southern cotton). Into the vacuum stepped "yankee ingenuity" a term which represents Americans willingness to make do with whatever resources they had close by in order fulfill needs that could not be satisfied by imports. Yankee ingenuity was viewed with a mixture of disdain and admiration by the British whose comparatively advanced industrial and technological resources produced most of the best manufactured products in the word at the time. The distain arose from the precarious quality of the Yankee solutions generated without proper training and resources. The grudging admiration arose from the fact that the Yankees could solve the problem at all. The Brazilian Portuguese equivalent "gambiarra" carries a similar meaning and stigma. Because Spain and Portugal 
prohibited their colonies from manufacturing their own goods as a rule, what would have been called "yankee ingenuity" in the 13 colonies would be called "illegal production" and punished accordingly in the Iberian colonies.

Two centuries after Americans were recognized for their improvisational and informal abilities, the French anthropologist Levis Strauss (1963) identified the ability to make do with what is at hand as "bricolage"-the creative process that was responsible for all of the technological advances of the neolithic age including pottery, metallurgy, archery, agriculture, baking, cheese making and many other innovations and technologies. The abilities developed through bricolage are now recognized in a fast growing stream of research as the major alternative to formal rationality as a source of innovation, and because the formal theories and methods of science and engineering frequently break down when faced by new challenges, it has now been firmly established that many technological and market innovations in all of the high tech fields have their origin in bricolage (Baker \& Nelson 2005). It is highly likely that American bricolage was partially responsible for the wave of American innovations, particularly during the 1800 s which help catapult the US to world economic and technological dominance.

\section{Individualism versus Spontaneous Sociability}

Aggressive individualism and mistrust of central authority have doubles fueled an innovative and practical spirit in the US, but it would seem that there are limits to the benefits of individualism and iconoclasm especially in the current modern economy. Francis Fukayama (1995) poses a provocative argument about individualism and major economic innovations in his now classic book Trust which attempts to identify the limits of unrestrained individualism for economic and social prosperity. The view he develops of both US technological and innovative prowess is counterintuitive in many ways and merits inclusion and analysis here. To mercilessly summarize a long and masterful book filled with deep arguments and exhaustive comparative historical content, Fukayama argues that to generate the most ambitious and technologically sophisticated innovations and successfully diffuse them into broad markets requires very large private hierarchies, i.e. large, diverse and capital and technology intensive firms like Intel, Siemens, Mitsubishi, General Electric, Honda, or Boeing. These massive and complex hierarchies in turn cannot rely fully 
on bureaucratic formal organization because purely hierarchical forms are too unwieldy and above all too balkanized and differentiated to successfully produce, perfect, sell, install, and service complex products which have never been made before.

In order to do so, according to Fukayama, these dominant firms must be populated by people who set self interest aside in the pursuit of common goals. In most human societies, self interest is traditionally only set aside in tightly knit familial or clan groups. Outside of the primary group, mistrust and exploitation dominate and any complex coordinated action faces nearly insurmountable barriers. Only a minority of societies have cultures which permit "spontaneous sociability" that is, the ability to trust and act transparently with relative strangers. These societies, most notably Japan, Germany, the Netherlands, Switzerland Sweeden, and-surprise--, the United States, field the largest technologically complex and innovative private enterprises and therefore occupy the technological high ground worldwide. Other societies, although close neighbors like Italy, France, Taiwan, and Mexico cannot compete in these markets because spontaneous sociability does not permit that kind of complex large scale coordination.

Fukayama dedicates large portions of his book to arguing that, contrary to the individualistic stereotype held both informally and codified in many comparative works (like Gert Hofstede's 1984;1985) the United States is more similar to Germany and Japan than it is France, or China in terms of "spontaneous sociability." He bases his arguments on the preponderance of community based solidaristic organizations arising from aggressive proselytizing by protestant churches and by the comparative equality engendered by the large American frontier and the absence of a dominant church and state bureauracy. He notes however, that this cultural capital faces serious challenges because of immigration, cultural diversity, secularization, prosperity, the growth of the state, and other factors.

Fukayama's argument is provocative because he develops in detail the idea that effective hierarchies are dependent on a certain type of cultural milieu. This position is provocative because of its relationship to the transaction school of economics and organization theory. In a nutshell, transaction costs theory argues that as transactions become more complex, the mechanisms for preventing transacting parties from self interested, opportunistic action, progress from markets 
supported by the legal system, to hierarchies supported by a far reaching employment relationship, to "clans" in which socialization into a strong culture imbues parties with a strong predisposition against opportunistic behavior. Thus in the traditional transaction costs perspective, organizational culture only comes into play when transactions are complex and involve a high risk of exploitation. Buying grapes for instance requires little effort to guarantee the transaction. One need only taste a small sample and compare prices to choose a transacting partner. Only in the case of a false scale or perhaps contaminated product might the legal system become involved. A more complex transaction such as a major software project for an unusual business might prove more effective by hiring a trustworthy employee than contracting an outside supplier. Something very complex and sensitive like brain surgery could require a renowned surgeon who is trusted in the community, has taken the Hippocratic oath, and was trained and socialized by a prominent university. Using this perspective, culture is largely inoperative when the transaction is simple.

Fukayama's contribution here is to claim that hierarchies are culturally sensitive also. If the dominant culture is personalistic, requiring long term knowledge or kinship ties, the scope of the hierarchy will be limited. If by contrast the culture supports spontaneous sociability, people with no former contact will be able to relate with minimal opportunism, permitting larger and more effective institutions.

\section{Market or Bazar?}

What Fukayama does not stress, which we consider increasingly important, is the Weberian notion that, like hierarchies or clans, markets too are fragile and depend on culture. Weber argued that the neoclassical "market" which economics takes for granted, is actually supported by a long process of social evolution including citizenship, equality under law, a professional bureaucratic state, and other mechanisms-some of which look very much like what transpired during the formative period of the political institutions and social values of the English and in many ways were extended in the North American case. This long chain of institutional development and social evolution is what makes possible impersonal atomistic markets which are nonetheless efficient and not patently exploitative. According to conventional transaction costs thinking by contrast, markets exist in a relative cultural vacuum, requiring little institutional evolution to operate adequately. 
This is understandable because economics was developed during the British industrial revolution in which atomistic markets which were the heritage of the peripheral position and, early revolutions mentioned above in addition to other cultural factors beyond our scope here. As a result, economics as a discipline faces the "fish knows nothing about water" lack of marginality mentioned in tour introduction. Thus when a transaction costs economists utters the word "market" $\mathrm{s} /$ he invokes a concept which is alien in many if not most cultural contexts. As a means of exposing the cultural underpinnings of the neoclassical "market" We turn now to a short description of the "bazar" which was the dominant mechanism for economic exchange before the development of impersonal markets and which still dominates many exchanges in the trust cultures and some exchanges in high trust cultures.

When we free associate on the word "market" without any prior theorizing, many possible things come to mind, considerably more than come to mind when we say hierarchy or clan. The classical economist definition of market as "more than one seller and at least one buyer unimpeded by traditional or legal restrictions" in some ways is a hopelessly optimistic even in wealthy countries. One might argue that a simple enumeration of the images that the word evokes might be more accurate or at least more complete. For many, the first thing that comes to mind is a physical structure usually located in a neighborhood close to residences in which a variety of food and nonfood items are sold. This meaning was dominant for me while I was a child. It corresponds to the Brazilian term "mercadinho" or "venda da esquina" and contains a raft of easily understood cultural associations for most people in traditional and transitional societies. The terms fair, open air market, farmers market, marketplace or "feira" in Portuguese evokes another set of associations and cultural motifs. The concept of a "stock market", or "capital market" is yet another with an amazing complexity of legal, cultural, and financial ramifications.

If one wants to understand how culture interfaces with the idea of the market, innovation, technology and perhaps even science I believe that prominent anthropologist Geertz's $(1978 ; 1979)$ study of the "bazar" may offer the best baseline definition of the most common type of large scale transaction system throughout human history. Geertz elaborated his description of the bazar during a long 
ethnographic inquiry into the central transactional institution in the Morrocan town of Serfrou. The Serfrou bazar lies on the intersection of two marjor caravan routes and reflects how mechanisms for exchange in traditional societies in which manufacturing, services, and trade all come together at a central location. The Serfrou bazar contains some 40 stalls owned and staffed by round 600 persons of different ethnicities and kinship networks. It offers the gamut of products and services in this economy - saddles baggage, leatherwork in general, blacksmithing, pottery, armaments, textiles, furs, currency exchange, raw and prepared foods, live animals, meat and so on. While ample direct competition exists in the bazar, competitors frequently joint venture or exercise brokerage between links of their transactional network. As an example, the master of a caravan might need fodder for his animals, may urgently require a new harness and saddle bags in order to resume his journey. He may also be interested in acquiring a shipment of dates which are more expensive where he is going, if he can sell some of the wheat he is carrying now.

Our caravan leader may know a grain broker in the bazar who is a distant relative, but whom he does not trust. He may also stay at an inn whose owner knows several artisans in the Bazar and our caravan master may himself have other contacts who in turn may have yet others. In a classical neoliberal market, it would theoretically be a simple matter for the master to visit the relevant stalls, get independent quotes and offers, select the best options and transact. Our master however knows that this would be a grave error. Quotes collected from strangers will be hopelessly inflated and worse, quality and delivery precarious. Moreover, if word circulates that he is carrying a large shipment of heavy grain he may risk assault because the grain shortage up north makes it a scarcity and because the weight makes it difficult to outrun pursuers. If he transacts with Salim, who has an "understanding" with local officials and nonofficials who can provide protection or negotiate safe passage he reduces the danger of harassment or assault. At the same time the master knows that the best harness maker in the bazar likes to trade for commodities and also has ties with local influentials who may help guarantee safe passage through some territory. The harness maker also owes the caravan master a favor because of he referred lucrative business from a relative. But the caravan master also knows that the innkeeper cannot abide the better harness maker and is close friends with an adequate craftsman. If he dismembers his transactions and 
disperses them across his network he may not be able to please all of his trading partners and he may not be able to negotiate terms a good as if he were to bundle all of his dealings within one network. In any event the caravan master will need to dedicate considerable thought and ingenuity as well as lots of face time with his contacts in the bazar in order to craft his best set of deals and it is unlikely that any set of deals can optimize all of the social and economic factors in play.

Thus when we attempt to analyze the forces that shape economic relations across the Moroccan bazar, the costs of "monitoring and enforcing" a agreement between parties-normally defined as transaction costs (Coase; 1937 Williamson, 1975), loose analytical purchase because they are submerged in the "embedded" nature of the economic exchanges which take place (Granovetter, 1985). The Moroccan Bazar is not a Hierarchy nor a clan in the sense that both concepts presume less ambiguity about who commands and what norms govern interactions (Powell, 1990). Nor is it a market in any classical or neoclassical sense because the monetary meaning of prices is largely lost in the social calculus that goes into determining exchanges between embedded actors.

The individual orientation of the "baazari" in ways is close to Sarasvathy's (2001; 2008) effectuating entrepreneur-a construct which like bricolage arose and has grown as a variety of scholars have begun to acknowledge and explore the limitations of formal rationality that was presumed to have assumed unmitigated control of modern life. The classical economist views the entrepreneur as someone who scans the environment for new unfilled market opportunities, assesses the probability that investment in the opportunity will generate an acceptable return, and then invests resources in order to exploit the unfilled market need. By contrast, rather than scanning the general environment for likely opportunities, the effectuator scans her immediate identity, skills ad contacts and selects opportunities for exploitation not on calculated return offset by the perceived risk of failure, but by proximity offset by largest affordable loss. The effectuator asks herself "Who am I?, What do I know?, and Who do I know? and based on the answers makes a list of market offerings she could make offset by her answer to the question "What is the largest resource outlay that I am willing to loose in pursuing this opportunity?" S/he then proceeds with low risk initiatives that make creative use of her identity, contacts and skills. As these initiatives give her additional expertise, clarity as to identity and 
potential, and a more extensive social network, she may expand the scope of her initiatives to become progressively more aggressive and secure higher rates of return. As she expands and perfects these attributes she becomes more influential and capable and receives a broader variety more desirable proposals from her network.

Given the Shumpeterian $(1934 ; 1939)$ presumption that most innovations find their way to markets at the hands of entrepreneur, and given the degree of vibrant search behavior encountered in bazar settings, one might expect to find traditional markets rich in innovation, and indeed anyone who has spent any time in emerging markets comes away with admiration for the raw creativity and resourcefulness found. Without gainsaying the native creativity of effectuators and bricoleurs in traditional and emerging economies, it is important to stress a central difference between recent studies of bricolage and effectuation or even bootstrapping and what Geertz considers to be one of the most central aspects of bazar culture. While the assumption at least seems to be that entrepreneurial bricoleurs and effectuators have a rather open and collaborative relationship with their potential and realized trading partners, Geertz affirms that the baazari is immensely preoccupied with hiding all manner of relevant information on opportunities, resources, supplies, quality, and prices from others, many of which fall within Sarasvathy's "who I know" category. In so doing, they also reduce their partner's "what I know" category. Thus any adaptation of Sarasvathy's thinking for bazar economies would have to add several additional questions around "Do I want who I know to know what I am considering?", or "If I transact with who I know, will she steal my client?" and so on. In this sense our bazari is very different from Fukayama's spontaneous socializer who has been socialized to collaborate and share information with strangers without the long term courtship and intense negotiation that characterizes transactions between members of a bazar. And it is in this difference that I believe that much of the technological and innovation success of the high trust countries lies.

Consider for instance the likely impact of a bazar culture on social networks. Although baazari are doubtless constantly bumping into each other as they move about Serfrou, they are very careful about what they say and much more careful about who they choose to transact business with. Geertz makes clear that they prefer to rely on trading partners with whom they have longstanding ties and frequent contact. He also makes clear that arms length clients and suppliers and 
close trading partners get very different treatment. Given the importance of social networks for the generation and diffusion of innovations recognized since Rogers (2003) classic work, it seems a fairly simple matter to think about how bazar networks might be related. Density, tie strength, and factionalism are three major parameters of any social network. Density refers to the total number of contacts or "ties" that are realized of those which are possible among a set of actors. If our network contains 4 actors, six connections are possible if we do not consider asymmetries (a says he likes $B$, but $B$ says he does not like A) Thus if there are four contacts the network density is .8. If all actors are connected, density is one. Tie strength, which is closely related to multiplexity, refers to whether a tie involves reciprocity frequency, and positive affect. The presence of these three factors-I like you, I see you frequently, and we share favors, constitute a strong tie leading to multiplex transactional content. The absence of any of these elements means a weak tie. Factionalism refers to the degree to which ties in the network are confined to small groups or cliques who share high density contact with one another but low density with other groups. Factionalism can be calculated by summing all of the intergroup ties and dividing by the total of all ties. If all ties in a network occur internal to groups without any contacts linking diverse groups, factionalism is 1 . If all ties occur between groups-a logical and empirical contradiction--, factionalism would be 0 . High multiplexity and reliance on well known trading partners who negotiate face to face intensively typical of the bazar would logically be related to a comparatively high ratio of strong to weak ties. Strong ties are known to depress innovation but favor solidarity because the large socioemotional investment strong ties require reinforce similar world views, self censorship, distrust of outsiders, resistence to new ideas and groupthink. These effects would logically be compounded if strong ties are concentrated into tightly knit cliques of factions with little cross cutting ties to other cliques. Generally high density, by contrast would logically facilitate the flow of information throughout the network, ease the penetration of new ideas from outside, and weaken the power of brokers who realize benefits by providing third part links between otherwise unconnected parties. From what we know of bazar culture it would stand to reason that overall density would be low, strong to weak tie ratios would be high and factionalism would be high, particularly factionalism calculated on the basis of strong ties in the network. 
I heard echoes of the bazar network in a comparative study of intraorganizational networks from the USA and Brazil. Consider ratios computed from the network perceptions of 1307 managers from 54 US firms and 12 Brazilian firms (See Nelson \& Vasconcelos, 2004 for the complete study).

\section{US Brazil}

$\begin{array}{lll}\text { Factionalism computed from Strong Ties } & .531 & .654 \\ \text { Factionalism computed from Weak Ties } & .272 & .369 \\ \text { Ratio of Strong to Weak Ties } & .296 & .558 \\ \text { Density } & .56 & .30\end{array}$

These results, (which are all statistically significant) are fully consistent with our interpretation of Geertz' thinking as it would logically apply to networks in a bazar if we identify the Brazilian sample as bazar-like. Low density, high proportion of strong ties, and high factionalism are fully consistent with our interpretation of Geertz. Not only does this suggest that the bazar culture is more persistent in Brazilian organizations, it is consistent with the historical-cultural account we advance above.

Looking at the bazar through Fukayama's lens we would not expect to find the kind of coordination and focus that enables the great US, Japanese, and German multinationals to dominate high technology, science based, innovation driven industries, among other reasons because the calculus that determines alliances and transactions considers quality and competence only as incidental considerations or at best necessary but not sufficient factors. I believe It does however bear a strong resemblance to the kind of alliance building, horse trading, deal making and outright intrigue that characterize a range of settings found in both Fukayama's "high trust" (i.e. spontaneous sociability) and "low trust" nations. If we can accept Mary Douglas' (1985) insistence that similar subcultural patterns or matrices exist across diverse societies, the question may not be if we will find the bazar culture in high trust societies but in what proportionality and in what settings.

One of the most interesting and for our purposes relevant studies of cultures of technological innovation comes from Andrew Hargadon (2001), who has undertaken ethnographic research in knowledge intensive firms in Silicon valley with an intensity and perceptiveness which rival Geertz' long tenure in the Moroccan bazar. 
Hargadon's work is interesting among other reasons because after publishing several influential papers on technological innovation and organizational context in the Silicon valley region, he reached the conclusion that the overall configuration and morphology of the innovative process in the region closely resembles Geertz' bazar.

$\mathrm{He}$ begins his analysis by calling into question the factory and market metaphors which dominate thinking about knowledge work and finds them insufficient to capture the dynamic nature of the innovative process. In this regard he parallels Fukayama's arguments that market coordination is insufficient for major technological/market innovation, but he also faults the idea that a static hierarchy (the manufacturing metaphor) is adequate to the task. He sees Geertz' bazar as better suited because of three attributes of the bazar: Production and exchange are simultaneous and inseparable. 2. Effort and participation involve multiple currencies, 3. Work is grounded in a particular time and place. In his own words:

First, the production and exchange of knowledge are simultaneous and inseparable processes, and this inseparability creates the need for intensive interactions in order for participants to identify what past ideas and experiences are relevant to current problems. Second, the effort and contribution of participants are valued in multiple currencies; pay and promotion, as the most prominently economic of these currencies, is augmented by other rewards such as status within the organization and the maintenance (or creation) of a web of obligations. Third, knowledge work is grounded in a particular time and place and, as such, any one person's ideas and experiences fluctuate from highly valued to irrelevant or obsolete depending on the particulars and definitions of the problematic situation.

He then proceeds to provide several examples of how in silicon valley high tech firms, these dynamic, high interaction, flexible transaction networks are used to identify and court partners and ultimately to define opportunities and produce unique solutions. As is the case for parallels with both effectuation and bricolage, the similarity to the bazar is compelling. And like the bricolage and effectuation literatures, the intense distrust bordering on paranoia of the bazar is ignored. Quite to the contrary, Hargadon stresses the importance of a culture of trust to make his "Knowledge Bazar" work. Again in his own words:

For managers, building the organizational bazaar means creating the public spaces where these interactions can take place-often unexpectedly-and also building the social commons which shapes the actions and attitudes of 
knowledge workers as participants in the process. Part of the solution may lie in creating the conditions for a dynamic equilibrium, where territoriality and hoarding become ineffective tactics in the pursuit of self-interest. And part of the solution may lie in allowing the participants themselves to determine and evaluate who they work with and how often. These three aspects of knowledge work - the dynamic equilibrium, the embedded evaluation, and the physical and social commons-work together to create the conditions for knowledge work in the organizations studied here.

Thus we see a hybrid of market combined with hierarchy, but only able to function because cultural mechanisms exist to defeat or at least mitigate self interest. The analytical payoff of a prominent student of technology and innovation in the US is the idea that the bazar-- an ancient, perhaps the most ancient institutional mechanism for transactions-- is most descriptive of the way the most sophisticated technological innovations are produced and diffused. Paradoxically though, this ancient form only works for high technology because it is supported by more than a millineum of halting cultural and institutional development which permits the bazaar to function without the emdemic distrust that is its most defining nonstructural attribute.

\section{Conclusion}

We have taken a short somewhat chaotic tour of the relationship between the mechanisms that create and disseminate scientivic and technological artifacts and innovations across human systems with emphasis on the North American experience at times contrasted with the Iberian experience. The historical-cultural part of the excursion was easiest because the peculiarities that separate the British and North Amiercan experience are so clear and because the arguments are not new. The underlying themes of what I have covered above have been around for a long time and despite variations in interpretations the details and causal affirmations, the overall outline is little disputed.

However, when we come to the specific institutional forms associated with technological artifacts and market innovations, there is much ambiguity. Fukayama argues that spontaneous sociability permits the development of large technologically oriented hierarchies and demonstrates an associationbetween big hierarchies and a certain cultural- institutional matrices. However, there hierarchies all over the world and the fact that some are bigger than others may be important but it seems a lot on 
which to hang technological and innovative competitiveness. The story becomes even murkier when we mix in the Amiercan penchant for bricolage, which has existed since the stone age, and when a major authority on innovation affirms that a major if not the major institutional form used by high tech ventures in siicon valley looks like the same form that has been dominant for much trade since time immemorial.

My own meso level work comparing social networks inside Brazilian and USA organizations might suggest that not only the size but also the morphology of hierarchies may vary from high trust to low trust environments especially in regard to density, and the ratio of strong ties to others,so one could argue that the consequences of spontaneous sociability are felt not only in the size of hierarchies but in their internal configuration. Should this be the case, perhaps a next step would be to try to get some idea whether the morphology of Hargadon's silicon valley bazar is the same as Geertz' Moroccan bazar. My bet is that they are not. I suspect that endemic mistrust provokes much lower density, higher factionalism, and reliance on strong ties in traditional versus high trust settings. It may therefore be possible to distinghish morphologically between a high trust and low trust bazar and a high trust and low trust hierarchy much like Lammers and Hickson (2013) distinguished between "latin" and "nordic" and Adler and Borys (1996) distinguished between enabaling and coercive bureaucracies..

Anogher possible angle of approach might be simply to study the incidence of different arrangements and their technological or nontechnological uses across cultures. For this purpose I turn here to Mary Douglas' almost infinitely appicable grid-group theory. Douglas was interested in universal cultural regularities across societies, although she was slightly more interested in "modern" societies and their similarities to primitive societies than most anthropologists. In her 1966 book Purity and Danger, she argued that in modern as in primitive societies classification systems are necessary to psychological and cultural well being and that matter which is neatly classifiable generates a sense of purity and therefore safety, while matter which does not fit a classification system causes discomfort and is associated with impurity and danger

One critical reaction to this book was the observation of Basil Bernstein that not all cultural systems abhor the absence of order and classification. He described families in which children's chores, bedtimes, seating order at the table and so on 
were highly regimented and ordered and others in which all of these matters were subject to negotiation and mutual adjustment between members of the family. Subsequent studies of social class and family dynamics have replicated this observation and associate the more orderly style as typical of lower classes and the less regimented style as typical of the middle classes. It didn't take long for Douglas to find many settings in which the need for classification is not so great. A subsequent book, Natural Symbols (1970) explored some aspects of this variance. Douglas' more mature position represents a departure much classic thinking which presumes the existence of classification and order in any social system. We might expect her be feel quite at home in Geertz' bazar.

Over time, Douglas' scheme became more sophisticated and added a second dimension involving group boundaries. The resulting scheme had four quadrants based on dimensions which she ended up calling "grid" and "group". The grid dimension refers to the need for order, differentiation and classification. Elaborate caste systems and bureaucratic structures with minute job descriptions and wage and authority grades are high on the grid dimension. Douglas' group dimension refers to the degree of permeability in group boundaries. A group or social unit which demands time, compliance and emotional commitment from its members is high on the group dimension. Those that do not are low on the group dimension. Because primitive social units are typically inclusive, long lasting and demanding, the question of variance in group strength was probably not a major consideration in many preliterate cultures but in modern societies it is quite important.

Institutions vary radically in the strength of their boundaries, from the military and fundamentalist religious movements which demand and monitor the absolute loyalty to members, to facebook or twitter pages or groups, in which membership requires only a simple acceptance of the moderator and which do little to scrutinize or monitor contributions. Douglas' two dimensions yield four categories which she calls "positional", "enclave," "individualist" and "isolates". Their attributes are simple extensions of the different combinations of high or low group and grid states. The individualist setting demands little loyalty or adherence to classification. The neoclassical market, the barroom brawl, homosexual encounters in bath houses and many forms of prostitution come closest to this form. Everything is negotiable, nothing is permanent, little time is spent thinking of long term consequences, and evaluations, transactions, alliances, and dalliances are made and ended easily. 
Personal stature, individuality, intuition and dyadic chemistry are key here. It is likely that individualistic contexts are only found in a very primitive and volitile "state of nature" settings or in settings where a central authority is powerful enough to open up spaces for consenting adults to meet and transact business with little history and little future, but cultural homogeneity is insufficient to dampen individual effersence. An intuitive ordering of people and events may exist, but it is individualized and does not rely on stable social structures or symbolic schemes to work.

The enclave, with high entrance boundaries, long term relations and minimal distinction between the various members of the family or clan is reflective of the dynamics of more stable and homogenous cultures and offers a place for less ambitious, less gifted, more discriminated or suppressed, or oppressed groups of the population to find safety and identity. As Lalive de Epinay classified Chilean Pentecostal sects, the enclave creates a "refuge for the masses," providing a sense of belonging and equality. Enclaves are common in transitional societies where migrants moving from rural enclaves based on proximity and kinship attempt to cope with an impersonal and individualistic world by constructing new urban enclaves based on common religious or political beliefs supported by frequent interaction and strong group identity. They are also found anywhere people seek refuge from an unpredictable and apparently unfair world

The positional space is found in the upper strata of most societies. There are tightly knit groups also, but they are created from alliances between privileged clans who must be present at the center of the social system to defend their interests. The classification scheme of positional contexts may be based on meritocracy, as it formally is in the military, or on kinship, patrimony and inheritance, as is more likely to be the case in more traditional settings. In any case though, membership is selective, group boundaries are high and there is constant anxiety and competition around one's position in the internal hierarchy. Members of positional social units simultaneously deal with at least two sets of binary oppositions. First they must maintain their differentiation from the undesirable of the other three quadrants. Second, they must constantly monitor their position within the elite hierarchy of the positional space.

Douglas' last and most esoteric space is the isolate, where people do not share strong group affiliation but are subject to rigorous classification or differentiation. 
Slaves, prisoners, abductees, some oppressed minorities, and the insane held in mental institutions would be typical of this quadrant. There is little basis for belonging - only the bad luck of being enslaved, incarcerated or institutionalized. There is also no mechanism of self selection or biological or cultural heritage that unites members. There is however classification, control or structure in terms of rules, capricious guards, systems of oversight or fiscalization, discrimination or oppression. At many points in human history those who ended up on the wrong side in a conflict have provided most isolates. The danger for the psitionalists is that but over time isolates tend to develop a common group identity. The tendency of isolates to develop into enclaves and develop a system of binary opposition to provide self identity and explain the nature of their oppressors is a major danger that all systems of organized oppression face.

Those occupying an individualistic space are anomic by definition. They are normless by Durkheim's criteria, but at least they are free. Indeed Douglas' scheme helps us to understand that anomie and freedom go together. The individualists's world is not a very comforting place. The isolates have it worse though. They are both alienated because they are subject to a classification scheme which is externally imposed on them, yet they have no group identity or tradition with which to construct their own response to the other quadrants. We can graphically display how Douglas' culture theory helps us to understand the boundary conditions around binary opposition:

One of the important insights of Douglas mature theory, which is best exemplified by her book How Institutions Think, is the idea that her four quadrants do not just coexist side by side, but rather actively if often subliminally compete. The members of the enclave see the positionalists as elitist egoists with no sense of the brotherhood of man while they view individualists and unprincipled riff raff. The positionalists view the enclavists as hopless idealists with little competence and no taste or sense of class. The individualists see the enclavists as hopelessly doctrinaire and out of touch with the real world, and so it goes. In this regard Douglas applies the same competitive logic that Bourdieu applies to symbolic and social capital to institutional arrangements. There is constant implicit and explicit argument positioning one's institutional posture as superior to the others. Douglas goes so far as to affirm that the major conflicts that make up modern cultures revolve around different vantage points originating in different spaces in the grid group 
matrix and she produces sophisticated research in a number of policy areas illustrating specifically how this is the case and analyzing proposals and arguments from different culture theory spaces. She claims also that in every institutional setting, all four quadrants will find some expression and be used to focus and interpret conflict.

Mary Douglas' provocative framework raises many more questions than we can consider here, but it does provide two immediate and immense insights. First we notice that the two institutional mechanisms discussed in this paper-the hierarchy, and the bazar-- are unambiguously confined to two of Mary Douglas' quadrants: isolates and positional, so if we are looking for fruitful environments for innovation, we can immediately exclude half of our cultural options. The next insight prompts us to look at the possible impact of the noninvolved quadrants on the innovative quadrants. The proportion of disenfranchised isolates to enclaveists in the US population, even during slavery, was much lower than in most other countries, and much, much lower than the Iberian colonies. US immigrants who did not bring their sectarian enclave with them in their luggage were frequently invited to join one upon arrival during the great proselyting revival movements of the $19^{\text {th }}$ and early $20^{\text {th }}$ centuries. By contrast the lberians had 700 years of practice in imposing isolate subcultures. The the Reconquista and subsequent conquest of Latin America were dedicated to the enterprise of subduing an enemy and guaranteeing that they would remain submissive and isolated. For the American enclavists the bazar is filled with anomic individualists who must be tolerated because they lay golden eggs and sometimes make guilt ridden contributions to the enclaves. For the lberians positionalists the bazar is a dangerous place populated by individualists who are a dangerous potential source of instability and rebellion which must be kept from infecting the isolated at all costs. For this reason the bazar mast be carefully watched by the hierarchy at all times. For the Americans enclavists, the hierarchy is another source of golden eggs and frequent guilt ridden contributions to the sects. For the American individualists, the positionalists make for big, high margin clients, and provide an effective legal system when things in the bazar get our of hand.

Douglas' contributions are useful for us because when we confront them with different national settings we do indeed find cross cutting themes and morphological similarities but at the same time the comparative dominance of one quadrant, the 
ideological and cultural conflicts between quadrants and the historical relations and waxing and waning of quadrats help us to understand dynamics of technology and innovation across nations which would be more puzzling than it already is.

\section{References}

Adler, P., \& Borys, K. (1996). Two types of Bureaucracy: enabling and coercive. Administrative Science Quarterly 41(1), 61-69.

Baker, T., \& Nelson, R. E. (2005). . Creating something from nothing: resource construction through entrepreneurial bricolage. Administrative Science Quarterly, 50, 329-366.

Barley, S. R. (1990). The alignment of technology and structure through roles and networks. ASQ 33, 61-103.

Berger, P. L., \& Luckman, T. (1967). The Social Construction of Reality. New York: Doubleday.

Coase, R. (1937). The nature of the firm. Economica, 4, 386-405.

Dacin, M. T., Marc, J. V., \& Brent, D. B. (1999). The embeddedness of organizations: dialogue \& directions. Journal of Management, 25.

Douglas, M. (1985). How institutions think. Syracuse NY: Syracuse University Press.

Fukuyama, F. (1996). Trust: human nature and the reconstitution of social order. Simon and Schuster.

Geertz, C. (1978). The Bazaar Economy: Information and Search in Peasant Marketing. American Economic Review, 68, 28-32.

Geertz, C. (1979). Suq: The Bazaar Economy in Sefrou. In C. Geertz, et al. (Eds.). Meaning and order in Moroccan society : three essays in cultural analysis. Cambridge: Cambridge University Press.

Gibson, C. (1967). Spain in America. New York: Harper Colophon.

Cornell University. (2017). The Global Innovation Index 2017 Report. Ithaca, NY:

Cornell/INSEAD/WIPO. Retrieved from https://www.globalinnovationlndex.org/gii2017-report. 
Granovetter, M. (1985). Economic Action and Social Structure: The Problem of Embeddness. Social Structure and Network Analysis, 91, 481-510.

Guillén, M. F. (2001). The limits of convergence: Globalization and organizational change in Argentina, South Korea, and Spain. Princeton University Press.

Hargadon, A. W. (2001). The firm as knowledge bazaar. [Working Paper]. University of California Davis.

Harrison, L. E. (1985). Underdevelopment is a state of mind. Lanham, MA: Madison.

Hofstede, G. (1984). Culture's consequences: International differences in workrelated values. Sage, 5 .

Hofstede, G. (1985). The interaction between national and organizational value systems. Journal of Management Studies, 22(4), 347-357.

Jenkins, S. (2012). A short history of England. London: Profile Books.

Lammers, C.J., \& Hickson, D. (2013). Organizations Alike and Unalike, (Vol. 17). London: Routledge

Lave, J. (1988). Cognition in practice: mind, mathematics, and culture in everyday life. Cambridge, New York: Cambridge University Press.

Middlekauff, R. (2007). The Glorious Cause: The American Revolution, 1763-1789. Oxford University Press.

Nelson, R. E., \& Vasconcelos, E. P. G. (2008). Information technology use, strategy, and subcultural environments: an exploratory study of Brazilian real estate agencies. The Electronic Journal on Information Systems in Developing Countries, 35, 1-10.

Nelson, R.E., \& Vasconcelos, E. P. G. (2004). Industry Environment, National Culture, and Verbal Networks in Organizations: An Exploratory Study. Management Research, 5, 135-148.

Powell, W.W. (1990). Neither Market nor Hierarchy: Network Forms of Organization. In B. M. Staw, \& L. L. Cummings (Eds.), Research in Organizational Behavior (pp. 295-336). Greenwich, CT: JAI Press.

Rogers, E. M. (2003). The Diffusion of innovation ( $5^{\text {th }}$ ed.). New York: Free press Edition.

Sarasvathy, S. (2001). Causation and effectuation: toward a theoretical shift from economic inevitability to entrepreneurial contingency. Academy of Management Review, 26, 243-263. 
Sarasvathy, S. D. (2008). Effectuation: elements of entrepreneurial expertise. Cheltenham: Edward Elgar Publishing.

Shumpeter, J. A. (1934). The theory of economic development: An inquiry into profits, capital, interest, and the business cycle. Cambridge: Harvard University Press.

Shumpeter, J. A. (1939). Business Cycles: A theoretical, historical, and statistical analysis of the capitalist process. New York: McGraw Hill.

Shenav, Y. A. (1999). Manufacturing rationality : the engineering foundations of the managerial revolution. Oxford, New York: Oxford University Press.

Wallerstein, E. (1980). The modern world system (vol. 2.). NY: Academic Press.

Williamson, O.E. (1975). Markets and Hierarchies: Analysis and Anti-Trust Implications. New York: Free Press. 